\title{
Freezing rain and sleet climatology of the southeastern USA
}

\author{
David A. Gay, Robert E. Davis \\ Department of Environmental Sciences, University of Virginia, Charlottesville, Virginia 22903, USA
}

\begin{abstract}
Freezing rain is a dangerous and economically costly event that occurs frequently in the southeastern United States. Using surface observations for 44 Southeast stations, we describe and map the basic climatological data for both freezing rain and sleet, and describe the number and duration of events and associated upper air temperatures, layer thicknesses, and temporal trends. The Southeast averages 1.6 freezing rain and sleet events per year, ranging from 0 in southern Florida to over 5 in highland Virginia. Event frequencies and durations show 2 general trends: (1) a mountain-coastal decrease, and (2) a north-south decrease. Differences between freezing rain and sleet are evident in the upper air analysis: freezing rain events have higher $850 \mathrm{mb}$ temperatures and lower surface temperatures. Freezing rain and sleet thickness differences show more variation for the 850 to $700 \mathrm{mb}$ layer and less variation for the 1000 to $850 \mathrm{mb}$ layer. Average 1000 to $500 \mathrm{mb}$ thicknesses for freezing rain and sleet are both above and below the traditional 540 dam thickness. The ratio of freezing rain to sleet is consistently 2.0 or 2.5 freezing rain hours to 1.0 sleet hour in the upland stations, but is as low as 0.5 to 1.0 along the coast.
\end{abstract}

\section{INTRODUCTION}

Ice storms are very dangerous and costly precipitation episodes. Although the glaze produced in these storms can be beautiful, the damage caused to tree limbs and trunks, power lines, structures, etc., and delays in transportation can be quite extensive. Each of these physical impacts has an economic cost to individuals, businesses, and landscapes of affected regions. Therefore, the timing and location of these storms, their frequencies and durations, and the damage they cause is of considerable interest to the general populace. Despite its socio-economic importance, little is known about the climatology of freezing rain and sleet (FR/Sl) in the United States.

The accepted theory of FR/Sl development involves snow falling through a surface inversion of warm air aloft and cold air at the surface (Stewart 1985). These events are generally associated with warm fronts in the Southeast. The observed surface precipitation type is defined by the depth of both the in situ cold and warm layers. As warm air intrusion continues in association with an approaching warm front, the depth of the warm layer increases, more snowflakes melt as they fall into the warm layer, and the chance of them refreezing in the shallower cold layer is reduced. For instance, snow is observed at the surface when the air throughout both layers is below $0^{\circ} \mathrm{C}$ (e.g. in Fig. 1 , after Stewart 1985). A mixture of frozen and unfrozen hydrometeors develops (e.g. sleet) as snow falls through a relatively shallow overlying warm layer (temperature, $\mathrm{T},>0^{\circ} \mathrm{C}$ ) and begins to melt. The still relatively deep cold layer $\left(\mathrm{T}<0^{\circ} \mathrm{C}\right)$ quickly supercools the hydrometeors to the ambient temperature. With supercooled temperatures, the remaining ice crystals provide efficient, preferential sites for re-freezing and $\mathrm{Sl}$ is the likely observed surface precipitation type. As the warm layer deepens (e.g. freezing rain), snowflakes are completely melted and only water droplets remain at the warm-cold layer boundary. Again, the cold layer supercools the droplets, but without ice crystals present, little, if any, re-freezing occurs and the likely observed surface precipitation type is FR. Objects on the ground must be at or below freezing for FR to occur. Thermometers in above-ground shelter can measure above-freezing temperatures even with below-freezing ground temperatures when microinversions are in place. With liquid droplets reaching 

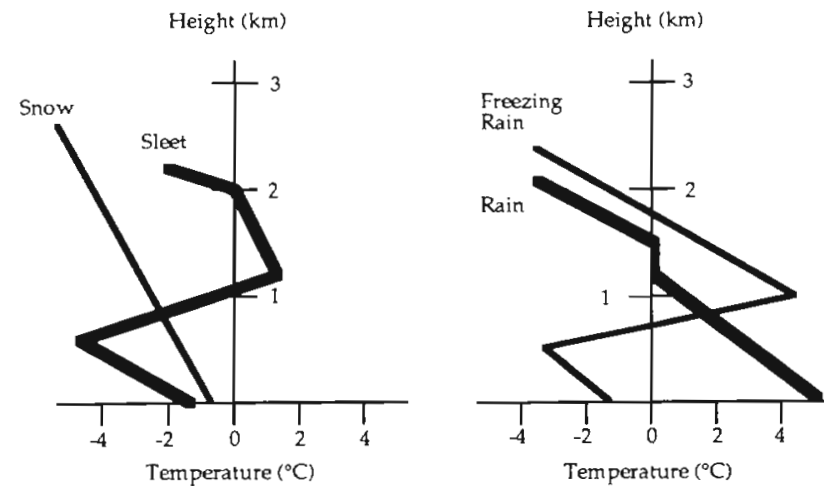

Fig. 1. Vertical temperature profiles leading to 5 observed surface precipitation types: snow, sleet, freezing rain, and rain (from Stewart 1985)

the ground (e.g. rain) and surface temperatures above freezing, the observed precipitation will be cold rain (Stewart 1985). McQueen \& Keith (1956), after Okada (1914) and Brooks (1920), suggest that Sl can form from completely melted raindrops, given strong low-level winds that: (1) maintain a deep, cold layer, and (2) 'create a stirring action' that increases the likelihood of re-freezing droplets.

With the approach of a warm front, the deepening warm layer melts more and more snow while the surface remains under cold air throughout. This leads to a commonly observed progression of precipitation types from snow, to $\mathrm{Sl}$, to $\mathrm{FR}$, and finally to rain. This is the normal occurrence in the Southeast, as most FR/Sl events are thought to be associated with warm fronts. Martner et al. (1993) note that the reverse evolution (rain, FR, Sl, snow) occurs with cold frontal events in the southern Plain states. FR/Sl events have also been noted for stationary fronts and in non-frontal situations (Bennett 1959).

Several researchers have investigated individual FR/Sl storms and their characteristics in the Southeast and other regions (Brooks 1914, 1920, Tannehill 1929, McNayr 1944, McQueen \& Keith 1956, Young 1978, Donaldson \& Stewart 1989, Martner et al, 1993). FR and Sl tend to occur near low pressure centers. The rain-snow transition zone is usually found between 80 and $125 \mathrm{~km}$ on either side of an $850 \mathrm{mb}$ low center trajectory (Spiegler \& Fisher 1971, Eagleman 1983). However, Ackely \& Itagaki (1970) noted a wider area (ca $280 \mathrm{~km}$ ) of frozen precipitation on either side of the storm's track. The frozen/unfrozen boundary is delineated by the $0^{\circ} \mathrm{C}$ isotherm, with warmer air to the right of the storm's track and with colder air behind and to the left (Stewart 1991). FR tends to be found in bands along the warm front and primarily to the right of the surface low's path (Donaldson \& Stewart 1989). Young (1978) observed these same- sized FR bands preceding the warm front (warm overrunning).

The temperature structure (and resulting thickness) of the atmosphere is very important in determining the precipitation type observed at the surface. FR has below-freezing surface temperatures and above-freezing upper air temperatures (McQueen \& Keith 1956 , Bennett 1959, Young 1978, Martner et al. 1993). Lamb (1955) found that European storms with freezing levels of $300 \mathrm{~m}$, a 1000 to $700 \mathrm{mb}$ thickness of $2780 \mathrm{~m}$, and/or a 1000 to $500 \mathrm{mb}$ thickness of $5225 \mathrm{~m}$ had an equal probability of frozen or unfrozen precipitation. In Ontario, Canada, Koolwine (1975) found mean FR 850 to $700 \mathrm{mb}$ and 1000 to $850 \mathrm{mb}$ thicknesses to be $1539 \mathrm{~m}$ and $1313 \mathrm{~m}$, respectively.

Surface conditions change rapidly during a $\mathrm{FR} / \mathrm{Sl}$ storm. As a warm front event proceeds, pressure and wind speed generally decrease while temperature tends to increase and precipitation changes from snow to Sl to FR to rain (Bennett 1959, Stewart \& King 1987. Martner et al. 1993). It has been well documented that hydrometeor phase changes, both aloft and at the surface, can warm or cool ambient temperature depending on the local conditions, or can lead to a persistence of a $0^{\circ} \mathrm{C}$ temperature (Stewart \& Yiu 1993). The precipitation progression can often be complex, oscillating from snow to rain to snow with intermixed FR and Sl (Stewart \& Patenaude 1988), and have highly variable precipitation rates (McQueen \& Keith 1956). Higher

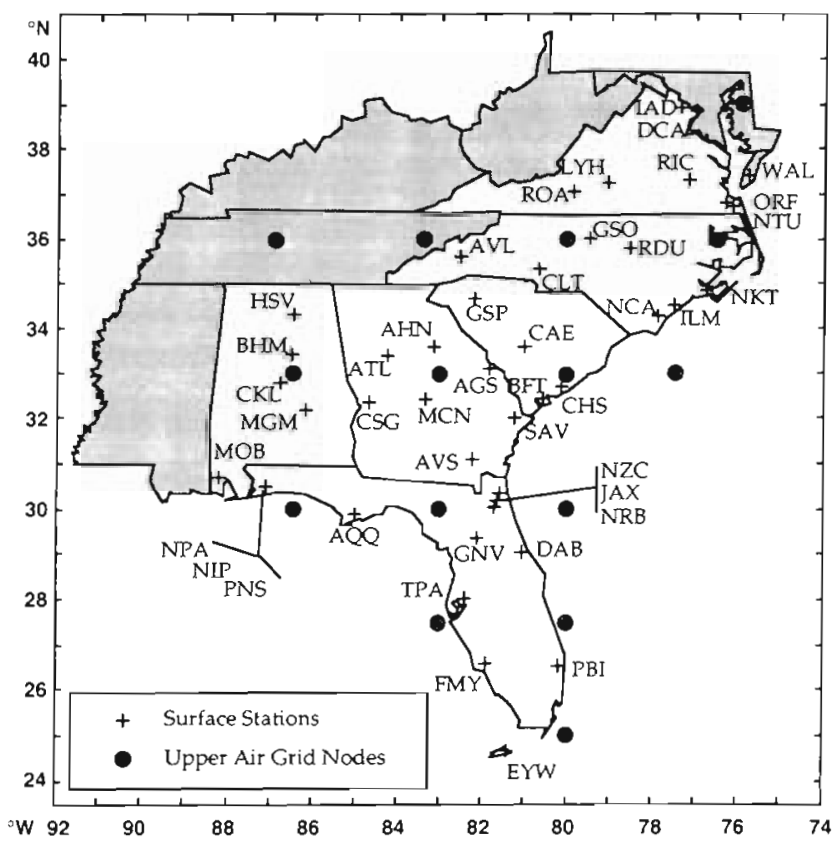

Fig. 2. Location of surface stations and upper grid nodes across the southeastern United States, identified with the 3 digit airways code (see Table 1) 
precipitation rates are associated with Sl, while lower precipitation rates are found with FR (Matsuo et al. 1981). Relative humidity also affects the observed precipitation type (through evaporation and condensation) with higher relative humidities leading to more FR, and vice versa (Matsuo et al. 1981).

Different surface types, plant characteristics, and geography can lead to highly variable surface impacts. For instance, urban areas have been shown to have fewer FR events than rural sites, presumably because cities maintain surface temperatures above freezing longer than surrounding areas (Bennett 1959, Ackely \& Itagaki 1970). Pooled, cold air along coastal areas and east of the Appalachians can increase FR frequency (Stewart 1992). Large inland water bodies can moderate local temperatures and reduce glaze accumulation (Bennett 1959). Damage in forests has been noted as higher for (1) older, less pliable trees, (2) deciduous trees (vs coniferous), (3) north- and eastfacing slopes, (4) higher slope elevations (Downs 1938), and (5) windward slopes through glaze/wind interactions (Bennett 1959).

In this research, our goal is to provide a basic climatology of FR/Sl events for the southeastern USA. We discuss and map the number and duration of FR/Sl events, investigate the average upper air structure during these events and compare our results to those of previous research for other regions. Freezing rain is defined as:

'Rain that falls in liquid form but freezes upon impact to form a coating of glaze upon the ground and on exposed objects... While the temperature of the ground surface and glazed objects initially must be near or below freezing $\left(32^{\circ} \mathrm{F}\right)$, it is necessary that the water drops be supercooled before striking...'

(Huschke 1959).

Freezing drizzle is the same basic phenomenon with a smaller drop radius $(<0.2 \mathrm{~mm})$. Although the term 'sleet' commonly has several meanings, here $\mathrm{Sl}$ is a specific type of ice pellet 'consisting of transparent or translucent pellets of ice, $5 \mathrm{~mm}$ or less in diameter' (Huschke 1959). It does not include the popular usage of sleet as a mixture of rain and snow.
Table 1 Surface station data for each of the 44 Southeast stations, including the 3-digit airways code, station longitude, latitude, elevation (m), and the first observation date used

\begin{tabular}{|c|c|c|c|c|c|}
\hline Code & Station & $\begin{array}{l}\text { Longitude } \\
\text { ('W) }\end{array}$ & $\begin{array}{l}\text { Latitude } \\
\qquad\left({ }^{\circ} \mathrm{N}\right)\end{array}$ & $\begin{array}{c}\text { Elevation } \\
\text { (m) }\end{array}$ & $\begin{array}{l}\text { Start } \\
\text { date }\end{array}$ \\
\hline AGS & Augusta, GA & 81.85 & 33.15 & 45 & Jul '50 \\
\hline AHN & Athens, GA & 83.19 & 33.57 & 247 & Jun ' 49 \\
\hline$A Q Q$ & Apalachicola, FL & 85.00 & 29.90 & 11 & Jun ' 49 \\
\hline ATL & Atlanta, GA & 84.26 & 33.39 & 315 & Jun '49 \\
\hline AVL & Asheville, NC & 82.55 & 35.60 & 661 & Jun ' 49 \\
\hline AVS & Waycross, GA & 82.24 & 31.15 & 45 & Jun ' 49 \\
\hline BFT & Beaufort, SC & 80.55 & 32.40 & 10 & Jun ' 49 \\
\hline BHM & Birmingham, AL & 86.45 & 33.34 & 192 & Jun ' 49 \\
\hline CAE & Columbia, SC & 81.07 & 33.57 & 69 & Jun ' 49 \\
\hline CHS & Charleston, SC & 80.12 & 32.65 & 15 & Jun ' 49 \\
\hline CKL & Centerville, AL & 86.80 & 32.90 & 43 & Dec '70 \\
\hline CLT & Charlotte, NC & 80.70 & 35.30 & 234 & Jun '49 \\
\hline $\mathrm{CSG}$ & Columbus, GA & 84.70 & 32.40 & 120 & Jun 49 \\
\hline DAB & Daytona Beach, FL & 81.03 & 29.11 & 12 & Jun 49 \\
\hline DCA & Washington National, VA & 77.02 & 38.85 & 20 & Jun '49 \\
\hline EYW & Key West, FL & 81.45 & 24.70 & 6 & Jun '49 \\
\hline FMY & Fort Meyers, FL & 81.70 & 26.35 & 4 & Jun '49 \\
\hline GNV & Gainesville, FL & 82.16 & 29.41 & 50 & Jun ' 49 \\
\hline GSO & Greensboro, NC & 79.57 & 36.05 & 270 & Jun ' 49 \\
\hline GSP & Greenville, SC & 82.25 & 34.70 & 296 & Oct ' 62 \\
\hline $\mathrm{HSV}$ & Huntsville, AL & 86.46 & 34.39 & 196 & Sep '58 \\
\hline IAD & Washington Dulles, VA & 77.40 & 38.90 & 98 & Nov' 62 \\
\hline ILM & Wilmington, $\mathrm{NC}$ & 77.90 & 34.25 & 12 & Jun' 49 \\
\hline JAX & Jacksonville, FL & 81.50 & 30.30 & 9 & Jun ' 49 \\
\hline LYH & Lynchburg, VA & 79.12 & 37.25 & 286 & Jun' 49 \\
\hline $\mathrm{MCN}$ & Macon, GA & 83.39 & 32.42 & 110 & Jun ' 49 \\
\hline MGM & Montgomery, AL & 86.24 & 32.18 & 62 & Jun ' 49 \\
\hline $\mathrm{MOB}$ & Mobile, AL & 88.15 & 30.60 & 67 & Jun ' 49 \\
\hline NCA & New River, NC & 77.55 & 34.50 & 8 & Jun ' 49 \\
\hline NIP & Milton, FL & 87.01 & 30.50 & 53 & Jun ' 49 \\
\hline NKT & Cherry Point, NC & 76.70 & 34.85 & 11 & Jun ' 49 \\
\hline NPA & $\begin{array}{l}\text { Pensacola/Forest } \\
\text { Sherman, FL }\end{array}$ & 87.19 & 30.40 & 10 & May'55 \\
\hline NRB & Mayport, FL & 81.55 & 30.23 & 6 & Jul '55 \\
\hline NTU & Oceanus Naval A.S., VA & 76.01 & 36.75 & 8 & Jun ' 49 \\
\hline $\mathrm{NZC}$ & Jacksonville/Cecil, FL & 81.70 & 30.13 & 24 & Jun 49 \\
\hline ORF & Norfolk, VA & 76.12 & 36.80 & 9 & Jun 49 \\
\hline PBI & Palm Beach Int., FL & 80.06 & 26.41 & 6 & Jun ' 49 \\
\hline PNS & Pensacola, FL & 87.12 & 30.45 & 36 & Jun ' 49 \\
\hline RDU & Raleigh-Durham, NC & 78.60 & 35.75 & 270 & Jun ' 49 \\
\hline $\mathrm{RIC}$ & Richmond, VA & 77.20 & 37.30 & 50 & Jun ' 49 \\
\hline $\mathrm{ROA}$ & Roanoke, VA & 79.90 & 37.05 & 358 & Jun 49 \\
\hline SAV & Savannah, GA & 81.12 & 32.08 & 16 & Oct ' 50 \\
\hline TPA & Tampa Bay Int., FL & 82.40 & 27.90 & 3 & Jun ' 49 \\
\hline WAL & Wallops Island, VA & 75.75 & 37.40 & 3 & Oct ' 63 \\
\hline
\end{tabular}




\begin{tabular}{|c|c|c|c|c|c|c|}
\hline Example & $\begin{array}{l}\text { Non-event } \\
\text { hours }\end{array}$ & Event hours & $\begin{array}{c}\text { Non-event } \\
\text { hours }\end{array}$ & Event hours & $\begin{array}{l}\text { No. of } \\
\text { events }\end{array}$ & $\begin{array}{c}\text { Duration } \\
\text { (h) }\end{array}$ \\
\hline 1 & & I h Sn, 2 h FR, i h Sl & $18 \mathrm{~h} \mathrm{R}$ & & 1 & 4 \\
\hline 2 & & $1 \mathrm{~h} \mathrm{Sn}, 23 \mathrm{~h} \mathrm{NP}, 1 \mathrm{~h} \mathrm{FR}$ & & & 1 & 25 \\
\hline 3 & & $1 \mathrm{hSn}$ & $24 \mathrm{~h} \mathrm{NP}$ & $1 \mathrm{~h} \mathrm{FR}$ & 2 & 1 each \\
\hline 4 & $6 \mathrm{~h} \mathrm{Sn}$ & & & & 0 & 0 \\
\hline 5 & $5 \mathrm{hR}$ & $2 \mathrm{hSn}, 1 \mathrm{~h} \mathrm{FR}$ & $8 \mathrm{hR}$ & & 1 & 3 \\
\hline 6 & & $1 \mathrm{~h} \mathrm{Sn}, 18 \mathrm{~h} \mathrm{R}, 1 \mathrm{~h} \mathrm{FR}$ & $10 \mathrm{~h} \mathrm{R}$ & & 1 & 20 \\
\hline 7 & $20 \mathrm{hR}$ & $1 \mathrm{hSl}$ & $20 \mathrm{~h} \mathrm{R}$ & & 1 & 1 \\
\hline
\end{tabular}

Event progression (elapsed time)

Fig. 3. Six hypothetical examples of FR/Sl 'events' (and 1 non-event) as defined here, including the 'observed' hour, the number of events, and the total event time. Shaded areas are hours not considered as part of the event. Sn: snow; R: rain; FR: freezing rain; Sl: sleet; NP: no precipitation

The upper air data source is the Northem Hemisphere Octagonal Grid Data (NCAR 1975), where upper air station observations were interpolated to a relatively square grid. Grid points between 25 to $40^{\circ} \mathrm{N}$ and 76 to $87^{\circ} \mathrm{W}$ were used, from January 1963 through December 1988 (Fig. 2). Observations were available at both 0000 and 1200 UTC for the 850,700 , and $500 \mathrm{mb}$ constant pressure levels. Temperatures at $1000 \mathrm{mb}$ were determined using surface temperature and elevation based on a lapse rate of $0.0098^{\circ} \mathrm{C} \mathrm{m}^{-1}$. While the use of both gridded data and information at only 4 standard reporting levels neglects much of the finer scale temperature information, this approach was necessary in a climatological study of this kind owing to the volume of data that we processed.

In our analysis, frozen precipitation observations were divided into 4 categories using TD 3280 present weather codes (PWCs): (1) Sl (PWC = ice pellets/pellet showers); (2) FR (freezing rain/drizzle, glaze); (3) snow (snow, snow showers/pellets/squalls/grains, ice crystals); and (4) other (all other codes). Two PWCs could be recorded for each hour and either code could be used to define $\mathrm{Sl}, \mathrm{FR}$, or snow. If 2 different PWCs reported frozen precipitation during the same hour, the hour was categorized in this order: $\mathrm{FR}, \mathrm{Sl}$, and snow.

In our data evaluation we discuss mean FR/Sl events. A FR/Sl 'event' was defined as 1 or more hours of reported FR or Sl without any intervening period (rain or no precipitation) longer than $24 \mathrm{~h}$, i.e. a continuous time period of frozen precipitation. A FR/Sl event can include snow, rain, or no precipitation, but must begin and end with some form of frozen precipitation. Events in which only snow was reported were not counted as FR/Sl events. Events recorded between May and September were assumed to be misreported and were removed. Also, during the middle and late 1960s, ob- servations were taken every $3 \mathrm{~h}$, so hours of FR and Sl are somewhat underreported during this period.

In Fig. 3, 7 hypothetical examples are shown as illustrations of this definition. In Example 1, $1 \mathrm{~h}$ of snow, $2 \mathrm{~h}$ of $\mathrm{FR}$, and $1 \mathrm{~h}$ of $\mathrm{Sl}$ are followed by $18 \mathrm{~h}$ of rain. This would be considered 1 event with a $4 \mathrm{~h}$ duration, with the rain following the FR/Sl event. Example 2 shows that $23 \mathrm{~h}$ of no precipitation between FR hours would not be long enough to define 2 separate events, but $24 \mathrm{~h}$ of intervening no precipitation (Example 3) would define 2 separate FR/Sl events of $1 \mathrm{~h}$ each. Example 4 contains only snow, and would not be a FR/Sl event. However, in Example 5, the event begins with snow which turns to FR after $2 \mathrm{~h}$ and therefore is classified as an event. This $3 \mathrm{~h}$ event has rain hours before and after, but they are not included as part of the event. Example 6 has only $1 \mathrm{~h}$ of FR, but does have frozen precipitation $19 \mathrm{~h}$ before (snow) and is therefore defined as a $20 \mathrm{~h}$ event. In Example 7 , the preceding or following $20 \mathrm{~h}$ of (non-frozen) precipitation would not be part of the $1 \mathrm{~h} \mathrm{Sl}$ event.

The event 'duration' was calculated as the total of 'event hours' - the total number of hours from the first reported to the last reported hour of frozen precipitation within $1 \mathrm{FR} / \mathrm{Sl}$ event. This could include hours with rain or without any precipitation as in Examples 2 \& 6 (Fig. 3).

As noted earlier, FR/Sl events are usually associated with frontal situations and rapidly changing surface and upper air conditions. Since FR/Sl events occur only under limited surface and upper air conditions, and since upper air characteristics change rapidly near fronts, all of the upper air data were restricted to reported FR/Sl hours occurring within $3 \mathrm{~h}$ of a 0000 or 1200 UTC upper air observation. Further, stations with fewer than 10 events were removed from the mapping, leaving Florida uncontoured in almost all figures. 


\section{RESULTS AND DISCUSSION}

The Southeast has an average of $1.6 \pm 1.7$ events $\mathrm{yr}^{-1}$. Most events occur in January, followed by December and February. Half as many events occur in December and February as in January. Regional event duration is longest in December with $9.0 \pm 7.1 \mathrm{~h}$ event $^{-1}$, followed closely by January and February $\left(8.7 \pm 5.4\right.$ and $8.6 \pm 5.8 \mathrm{~h}$ event $^{-1}$ respectively).

Comparisons of the number of events with both station latitude and elevation show linear relationships (Fig. 4). While the latitude relationship is fairly robust $\left(\mathrm{R}^{2}=0.68, F_{(1,42)}=88.1, \mathrm{p}=0.0001, \mathrm{MSE}=1.0\right)$, the elevation relationship is more variable $\left(\mathrm{R}^{2}=0.37, F_{(1,42)}=\right.$ 25.1, $p=0.0001, \mathrm{MSE}=1.9$ ). Events are less common as the frequency of cold air decreases with decreasing latitude and elevation (i.e. toward the south and the coasts). Asheville, NC (marked with a square in Fig. 4) has the highest elevation of all stations, but has fewer events per year than several stations at lower elevations. Wallops Island, VA (marked with a circle in Fig. 4), a coastal station with highly moderated temperatures, has an uncharacteristically low frequency of events for a high latitude station.

\section{Events}

The average number of events $\mathrm{yr}^{-1}$ is mapped in Fig. 5. There are 2 overall features to the map. First, there is a distinct $V$-shaped area of the highest events $\mathrm{yr}^{-1}$ extending from Washington, DC, to South Carolina and centered over Greensboro, NC. This area includes the stations with the highest event frequency - Roanoke, VA, Greensboro, NC, and Washington, DC

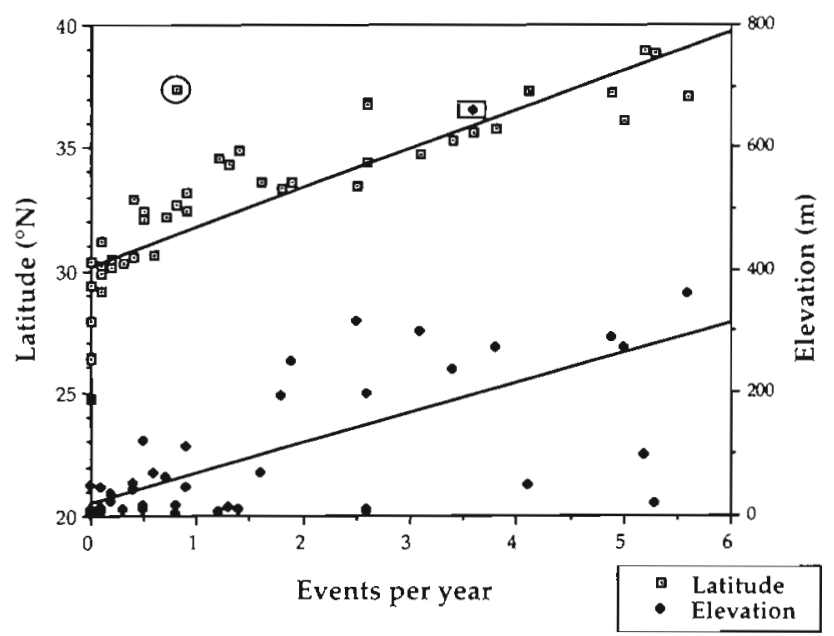

Fig. 4. Average frequency of events $\mathrm{yr}^{-1}$ as a function of station latitude and elevation. Two outliers (Asheville, NC, marked with a square, and Wallops Island, VA, marked with a circle) are discussed in the text

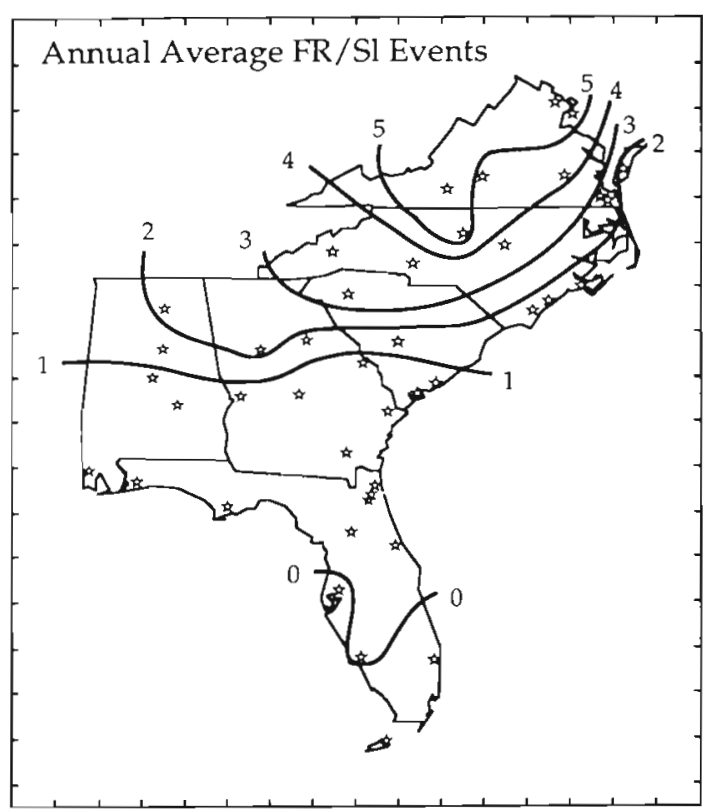

Fig. 5. Average number of FR/Sl events $\mathrm{yr}^{-1}$ in the southeastern U.S.

- each with over 5 events $\mathrm{yr}^{-1}$. The second feature is the rapid decline in the number of events between the piedmont and coastal areas in the north and from the mountains to the piedmont in the south. Along this gradient, the event number decreases from 3 or 4 events $\mathrm{yr}^{-1}$ to 1 or 2 events $\mathrm{yr}^{-1}$ over a distance of $200 \mathrm{~km}$. At the southern extreme, no hours of Sl or FR are recorded at the 3 Florida stations: Tampa Bay, Key West, and Palm Beach International. Interestingly, Fort Meyers, FL, reported 1 event with 1 h of FR.

These data suggest that the decreasing events gradients from upland to lowland areas and from north to south are most likely due to a decreasing prevalence of cold air and warm air intrusion from the oceans. These 2 processes rapidly decrease the event number between the inland stations and the coastal stations of Virginia and North Carolina, and in the Deep South where warm air intrusion is evident along the coasts and piedmont of South Carolina, Georgia and Alabama. Eagleman's (1983) maps also show these gradients and V-shape of maximum observations. Given that his 'days with glaze' is roughly equivalent to our events $\mathrm{yr}^{-1}$, we show excellent agreement with Eagleman except in western North Carolina where he maps higher frequencies.

The V-shaped area of cold air is a consistent monthly feature across the Southeast. Throughout the cold months, Roanoke, VA, Lynchburg, VA, Greensboro, NC, Washington, DC (National), and Washington, DC (Dulles) have the largest number of events. November is the only month where this ' $V$ ' feature is not clearly evident. Peak events per month are 1.3 December 
events in Roanoke, VA, 1.8 January events in Greensboro, NC, and 1.2 February events in Roanoke, VA, Lynchburg, VA, and Greensboro, NC. The region of strongest gradient migrates north and south as the mean position of the polar front (and the southerly advance of cold air) changes through the year. The total complement of mean and monthly maps can be found in Davis \& Gay (1993).

\section{Event durations}

Over the entire year, the average event durations are highest in Roanoke, VA, Greensboro, NC, and Washington, DC (Dulles) (over $6 \mathrm{~h} \mathrm{event}^{-1}$ ) and at the upland stations of Virginia, North Carolina and Georgia (not shown). Durations decline at the Georgia and Alabama piedmont along a north-south gradient. This pattern is not as clearly defined in the average winter months duration (December, January, and February) where the north-south gradient is prevalent only in the extreme southern regions (Fig. 6). Three of the upland stations average over $14 \mathrm{~h}$ event $^{-1}$ (Huntsville, AL, Asheville, NC, and Roanoke, VA). Between Lynchburg and Roanoke, VA, there is a difference of more than $4 \mathrm{~h}$ in average event duration. Most of the piedmont stations average between 10 and $12 \mathrm{~h}_{\text {event }}{ }^{-1}$. Jacksonville, FL, seems to be an outlier, where its elevated winter average is dictated by one $24 \mathrm{~h}$ event in 12 total events

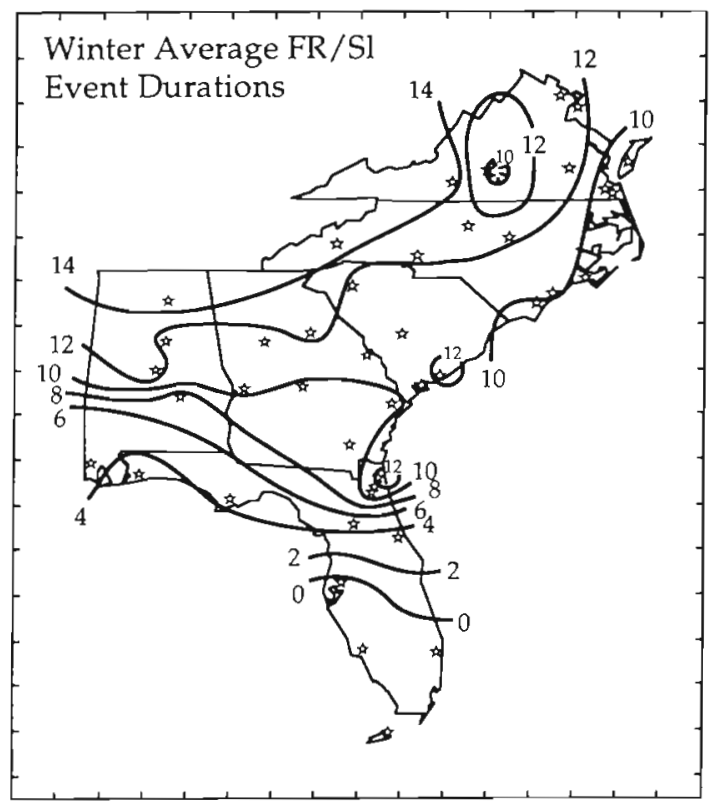

Fig. 6. Average hourly duration (h event ${ }^{-1}$ ) of $\mathrm{FR} / \mathrm{Sl}$ events for the winter months (January, February, and March) in the southeastern U.S

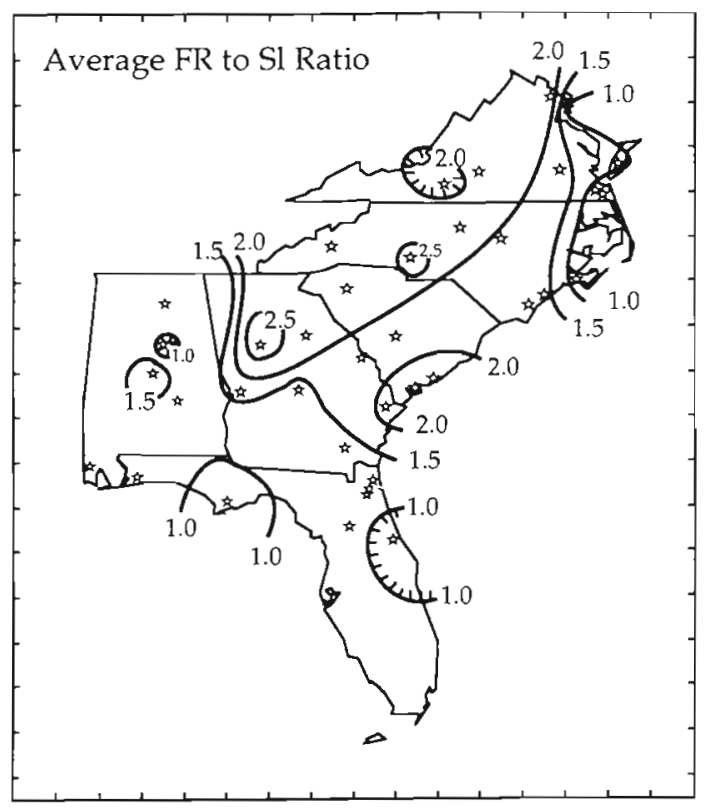

Fig. 7 Ratio of total reported FR hours to total reported SI hours in the southeastern U.S.

Event durations are consistent from month to month throughout Virginia, North Carolina, and South Carolina. Exceptions occur at the coastal stations and in upland Georgia and Alabama. In March, durations decline quickly south of the Appalachians, probably resulting from restricted advance of cold air. April events are extremely rare, with most stations reporting 2 or fewer events in $40 \mathrm{yr}$.

\section{FR/Sl ratios}

The ratio of (observed) FR hours to (observed) $\mathrm{Sl}$ hours is very uniform across the upland Southeast but varies markedly along the coasts (Fig. 7). Both FR and $\mathrm{Sl}$ are more prevalent inland, and each decreases towards the coasts. However, FR decreases 3 times faster than does $\mathrm{Sl}$, so there are fewer FR hours relative to Sl hours and a decreasing FR/SI ratio.

Most inland areas have ratios from 2.0 to 2.5 with maxima in Atlanta, GA, and Charlotte, $\mathrm{NC}(2.7$ and 2.5 respectively). The area is broad, covering most of the sites in Virginia, North Carolina, South Carolina and Georgia. It is interesting that Huntsville and Birmingham, AL (with ratios of 0.9 and 1.1 respectively) are much different from nearby upland Georgia stations. This FR/Sl ratio can be extremely sensitive to local effects, such as the development of cold air dams, inversions, and urban influences.

Many of the northern coastal stations have ratios at or below 1.0. Washington, DC (National) has a ratio of approximately 1.0 (767 observations), and Cherry 
Point, NC, Norfolk, VA, and Oceanus Naval Air Station (N.A.S.), VA, all have ratios less than 1.0 (more than 190 observations each). The same is true for several Florida stations, although this is based upon fewer observations. Exceptions include coastal areas of South Carolina and southern North Carolina, with ratios from 1.5 to 2.0 and higher. Low FR to Sl ratios $(\leq 1)$ are reported at stations with elevations below $200 \mathrm{~m}$ and less than 100 observed hours. Our hypothesis for this is that coastal stations, having ocean-moderated, warmer surface temperatures, experience less FR and a lowered FR/Sl ratio. Upland stations are colder and experience less warm air advection which leads to colder surface temperatures, more FR observations and larger FR/Sl ratios.

Washington, DC (National) may be an example of urban heat island influences decreasing FR occurrence. National Airport is located in the center of the Washington metroplex and has a FR/Sl ratio of 1.0 (767 observations over $40 \mathrm{yr}$ ), while Dulles Airport is located 30 miles east in semi-rural Virginia and has a ratio of 2.1 (642 observations over $25 \mathrm{yr}$ ). We propose that urban heating more frequently maintains surface temperatures above $273.0 \mathrm{~K}$, resulting in fewer FR observations and a lower FR/Sl ratio. Reduced FR in urban areas has been noted before by at least 2 researchers (Bennett 1959, for 2 Russian cities; Ackely \& Itagaki 1970, in the northeastern U.S.). Further, significant urban warming of temperatures in towns and cities is well documented (e.g. Ackerman 1985, Karl et al. 1988). Between 1961 and 1990, National Airport is consistently 2 to $4^{\circ} \mathrm{F}$ warmer on average throughout all months than Dulles (NCDC 1992). However, some warming at National may be partly due to moderating influences of the Potomac River. Between 1963 and 1989 (both airports operating), Sl observations were fairly consistent between National and Dulles Airports $(r=0.404)$. An unpaired, 2 sample $t$-test indicates that the Sl means are not significantly different $(\alpha=0.05)$ and neither time series has a significant trend. The same test for FR indicates that the means are significantly different.

\section{Surface and upper air temperatures}

Upper air temperatures during $\mathrm{FR} / \mathrm{Sl}$ events are important in determining the precipitation type observed at the surface. However, recall that our upper air data are gridded values which we assume are representative of large areas. This point is particularly important when using these values to discuss meteorological situations with highly variable temperature fields.

FR/Sl theory requires surface temperatures at or below $273.0 \mathrm{~K}$ for FR and suggests colder temperatures for Sl because of the necessity of a deep, cold layer. The average surface temperature differences between

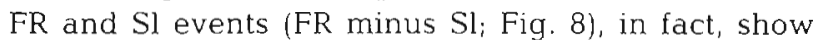
that most stations have colder temperatures for FR than for Sl (negative values). There are 4 exceptions to this finding, however (Athens, GA, Greensboro, NC, and Columbia and Greenville, SC). The FR temperature maximum is restricted by the requirement for freezing surface temperatures, but Sl does not have this surface temperature requirement. The largest temperature differences are found along the coasts and throughout the Deep South. The location of the $273.0 \mathrm{~K}$ surface isotherm under $\mathrm{Sl}$ conditions (not shown) corresponds very well with the location of the 2.0 FR/Sl ratio line (Fig. 7). This indicates that abovefreezing surface temperatures lead to reduced FR occurrence and a lower FR/Sl ratio, rather than more Sl. This correlation may be further affected by possible urban influences.

For FR, all of the mean surface temperatures are at or below 273.0 K (Fig. 9). Temperatures range from about 271.0 to above $272.5 \mathrm{~K}$ along a generally north to south gradient. Virginia and North Carolina coastal stations are warmer than equal-latitude inland stations, but the opposite is found for coastal South Carolina and Georgia. Mean surface Sl temperatures exhibit a higher variance for both below- and above-freezing values. The entire middle Southeast has surface Sl temperatures between 271.5 and $273.0 \mathrm{~K}$. Other stations, particularly those to the south, have mean temperatures above $274.5 \mathrm{~K}$ with the warmest surface temperatures at 2 northern coastal stations (Norfolk and Oceanus N.A.S., VA).

Positive temperature differences dominate at the $850 \mathrm{mb}$ level over the Southeast (Fig. 8), meaning that FR temperatures are higher than the corresponding Sl temperatures. Over all of Virginia, North Carolina, and South Carolina, the $850 \mathrm{mb}$ temperature differences are between 0 and $+3 \mathrm{~K}$. Over the State of Georgia, however, the differences are almost all negative (an observation for which we have no explanation). Furthermore, Mobile and Montgomery, AL, have the largest positive values of +6 and $+7 \mathrm{~K}$, while nearby Macon, GA, has a negative value of more than $4 \mathrm{~K}$

Almost all of the FR temperatures are in the same 'quadrant' of Fig. 9, with a majority of $850 \mathrm{mb}$ temperatures above $273.0 \mathrm{~K}$ and much warmer than surface FR temperatures. Most upland $850 \mathrm{mb}$ temperatures are between 273.0 and $276.0 \mathrm{~K}$ while temperatures are lower in the mid-Southeast and higher in the southern coastal and northern areas. For $\mathrm{Sl}$, the $850 \mathrm{mb}$ temperatures are generally lower than for FR, with temperatures ranging from less than 270.0 to $279.0 \mathrm{~K}$. The majority of upland temperatures are between 272.0 and $276.0 \mathrm{~K}$ and are about $1 \mathrm{~K}$ lower than FR temperatures. 


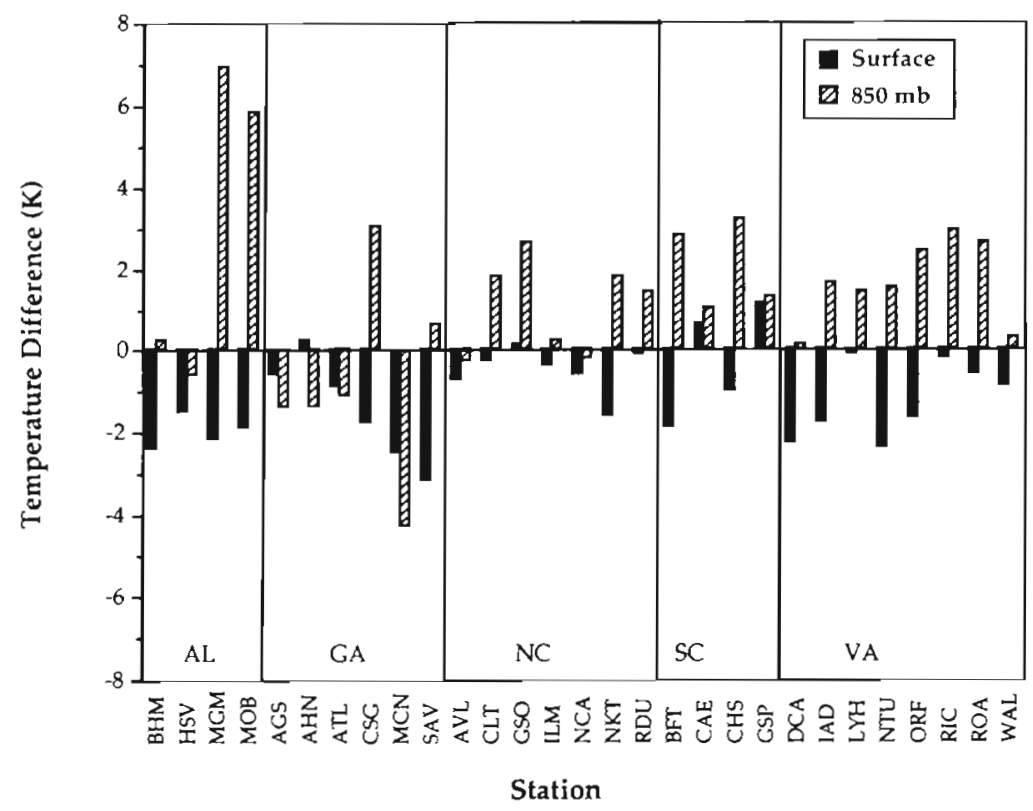

Fig. 8. Difference in mean temperature between FR and Sl events (FR minus Sl) for both $850 \mathrm{mb}$ and the surface, for each Southeast study site. Solid bar: $\Delta \mathrm{T}$ at the surface; hatched bar: $\Delta \mathrm{T}$ at $850 \mathrm{mb}$
Overall, surface temperatures are higher during Sl than during FR events at 25 of 29 sites shown and, at $850 \mathrm{mb}$, Sl temperatures are lower than FR temperatures at most sites outside of Georgia. Thus, the lowlevel inversion tends to be stronger during FR events, with a colder surface and a warmer $850 \mathrm{mb}$ level.

In other analyses of FR/Sl temperatures, Young (1978) found that FR temperatures for the southern U.S. averaged $277.25 \mathrm{~K}$ at $850 \mathrm{mb}$ and $271.50 \mathrm{~K}$ at the surface, in agreement with our findings. His average $\mathrm{Sl}$ temperatures, $269.75 \mathrm{~K}$ at the surface and $272.70 \mathrm{~K}$ at $850 \mathrm{mb}$, are much colder than both our temperatures and the findings of other researchers. Bryson \& Hare (1974) found average temperatures for mixed precipitation in Canada (FR, Sl, and snow/rain mixtures) to be $277.25 \mathrm{~K}$ at $850 \mathrm{mb}$ and between 268.00 and $273.00 \mathrm{~K}$ at the surface.

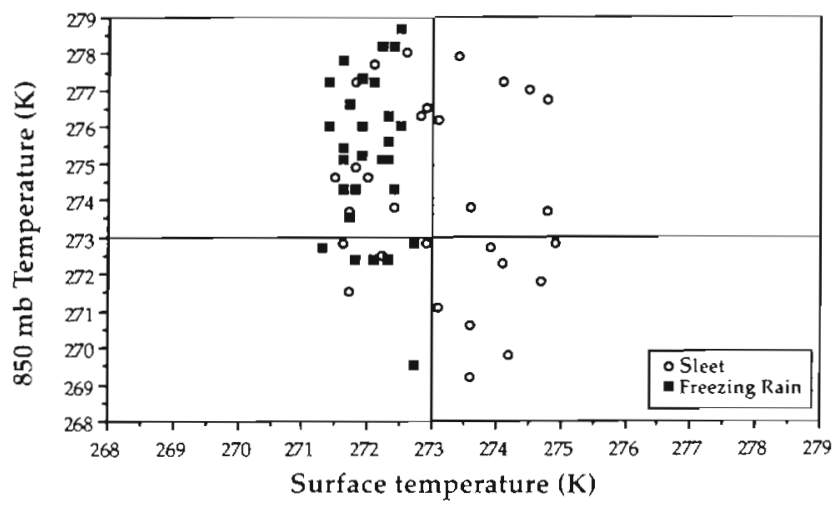

Fig. 9. Average surface and $850 \mathrm{mb}$ temperatures (K) for FR and Sl events

\section{Thickness}

Layer thicknesses have a large impact upon the surface precipitation type. Thicknesses are directly related to the average layer temperature according to the hypsometric (thickness) equation:

$$
Z_{2}-Z_{1}=\frac{R_{\mathrm{d}} \bar{T}_{\mathrm{v}}}{g_{0}} \ln \left(\frac{P_{1}}{P_{2}}\right)
$$

where the difference in height (thickness) of the layer bounds $\left(Z_{1}\right.$ and $\left.Z_{2}\right)$ is equivalent to the product of the average virtual temperature of the layer $\left(\bar{T}_{\mathrm{v}}\right)$, the $\mathrm{dry}$ air gas constant $\left(R_{\mathrm{d}}\right)$, the inverse of the average surface gravity force $\left(g_{0}\right)$, and the natural log of the layer boundary pressure ratio $\left(P_{1}\right.$ and $\left.P_{2}\right)$. Therefore, as a layer warms (virtual temperature increases), its thickness increases (Wallace \& Hobbs 1977). A 1000 to $500 \mathrm{mb}$ thickness of $5400 \mathrm{~m}$ is commonly used in forecasting to denote the snow-rain transition region (Heppner 1992).

During FR events, the central mountain and piedmont regions have mean 1000 to $500 \mathrm{mb}$ thicknesses between 5400 and $5460 \mathrm{~m}$ (Fig. 10). Over the coasts and southern U.S., FR accurs in warmer layers with thicknesses greater than $5460 \mathrm{~m}$. Based upon this map. the $5400 \mathrm{~m}$ thickness line should not be used as a 'general' rule for forecasting FR occurrence over the Southeast. Rather, this critical thickness varies significantly from station to station, which is also supported by Heppner (1992).

The 1000 to $850 \mathrm{mb}$ thickness map has the same 2 general characteristics, but there are areas with steep thickness gradients (Fig. 11). Thicknesses increase 


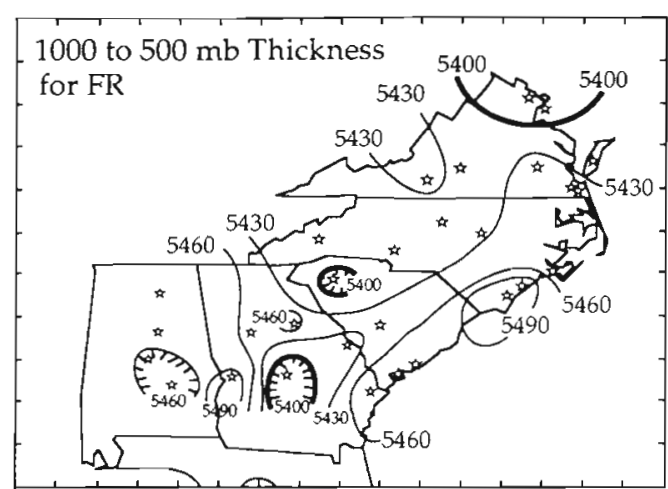

Fig. 10. Average thickness (m) of the 1000 to $500 \mathrm{mb}$ layer for FR events in the southeastern U.S. (excluding Florida peninsula)

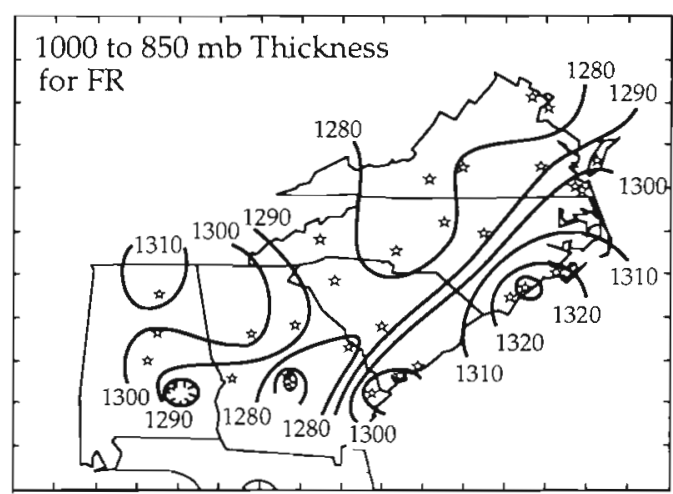

Fig. 11 Average thickness $(\mathrm{m})$ of the 1000 to $850 \mathrm{mb}$ layer for FR events in the southeastern U.S. (excluding Florida peninsula)

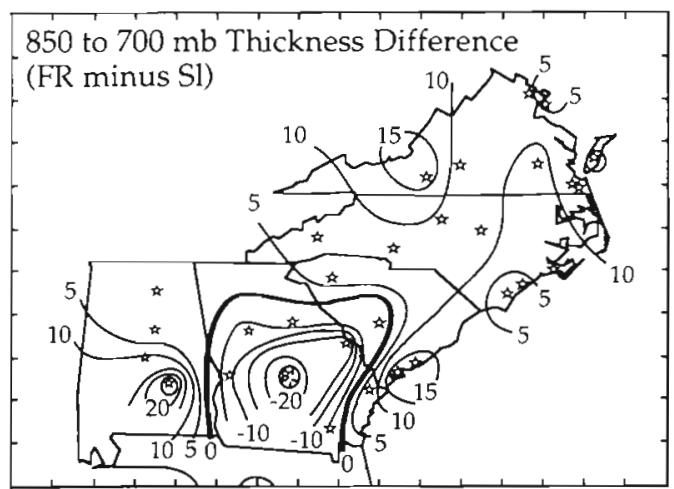

Fig. 12. Average thickness difference $(\mathrm{m})$ between FR and SI events for the 850 to $700 \mathrm{mb}$ layer (FR minus $\mathrm{Sl}$ ) in the southeastern U.S. (excluding Florida peninsula)

rapidly at the piedmont-lowland border. The upland thicknesses consistently average about $1280 \mathrm{~m}$, while coastal thicknesses are 1300 to $1320 \mathrm{~m}$. In southern Georgia and Alabama, thicknesses are comparable to those found in the upland regions. There are 2 groups present: (1) lower thicknesses (1280 to $1290 \mathrm{~m}$ ) for the central and northern upland regions, extreme northern coasts and the southern parts of Alabama and Georgia; and (2) higher thicknesses along the Atlantic coast and over upland Georgia/Alabama. Local ocean modification of temperatures accounts for the higher coastal thicknesses, and the frequency of resident cold air explains the lower upland thicknesses. Perhaps the deeper layers in north Georgia and Alabama are simply the result of a north-south gradient of temperatures in the upland regions. With this as an explanation, only Montgomery, AL, and Macon, GA, remain as colder outliers.

We computed average thickness differences between FR and Sl (FR minus Sl) for each station. The 1000 to $500 \mathrm{mb}$ thickness differences are positive in the central and northern regions, indicating that the entire layer is warmer during FR events. Conversely, Sl events have larger 1000 to $500 \mathrm{mb}$ thicknesses than FR events in the southern regions. Very large negative values (up to $60 \mathrm{~m}$ ) are present in central and southern Georgia. In southern Alabama, however, the values are largely positive and as high as $+120 \mathrm{~m}$. The 1000 to $850 \mathrm{mb}$ thickness differences across the entire Southeast (except for Macon, GA) are less than $\pm 10 \mathrm{~m}$. This indicates that, on average, thicknesses throughout this colder layer are similar for FR and Sl. The largest differences are found in the warm layer from 850 to $700 \mathrm{mb}$ (Fig. 12). In the northern areas, the differences are from +5 to $+15 \mathrm{~m}$, indicating that this layer is warmer for FR than for $\mathrm{SI}$. However, large negative values are present at Macon $(-25 \mathrm{~m})$ and throughout southern Georgia. A more variable upper layer thickness (850 to $700 \mathrm{mb}$ ) and a consistent lower layer thickness (1000 to $850 \mathrm{mb}$ ) supports the theory that the type of precipitation observed at the surface is strongly influenced by the state of the hydrometeor at the bottom of the warm layer.

Most of our FR/Sl thickness calculations compare favorably to those of other researchers (Fig. 13). Young's (1978) 1000 to $500 \mathrm{mb}$ FR thicknesses for the southern U.S. range from 5320 to $5510 \mathrm{~m}$ and average $5395 \mathrm{~m}$, slightly below the values for the majority of our stations. In Europe and England, the rain/frozen precipitation critical thickness is $5280 \mathrm{~m}$ (Lamb 1955) and $5225 \mathrm{~m}$ (Murray 1952), which are much smaller than our values for the Southeast. For the 1000 to $850 \mathrm{mb}$ layer, the rain/frozen precipitation critical thickness is $1314 \mathrm{~m}$ (Koolwine 1975), and Stewart \& Patenaude (1988) define a $30 \%$ probability FR/rain boundary thickness of $1298 \mathrm{~m}$. Both of these were measured in eastern Canada and fall in the middle of our distributions. 


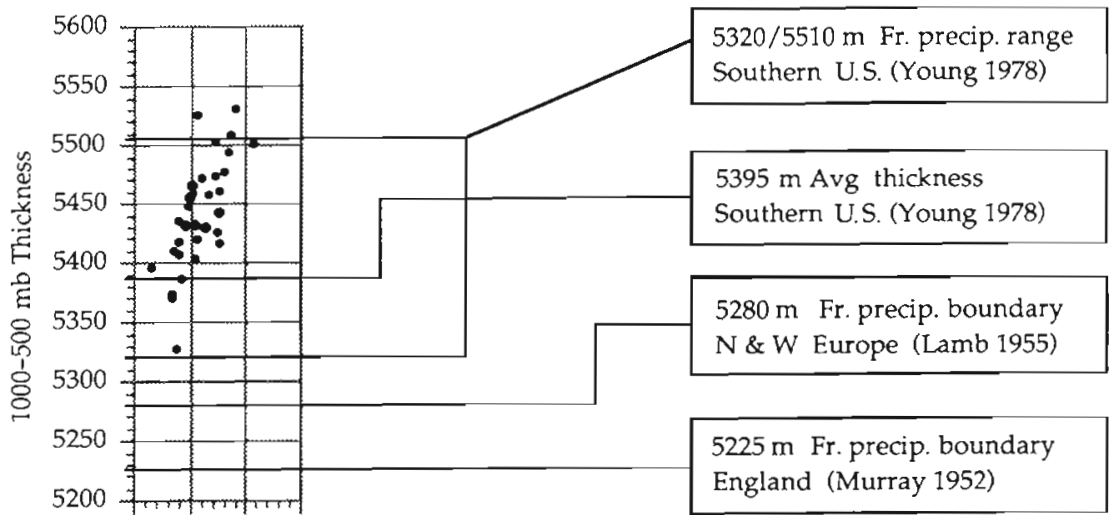

용

1000-850 mb Thickness

$1314 \mathrm{~m}$ Rain/FR Height

S. Ontario, Canada (Koolwine 1975)

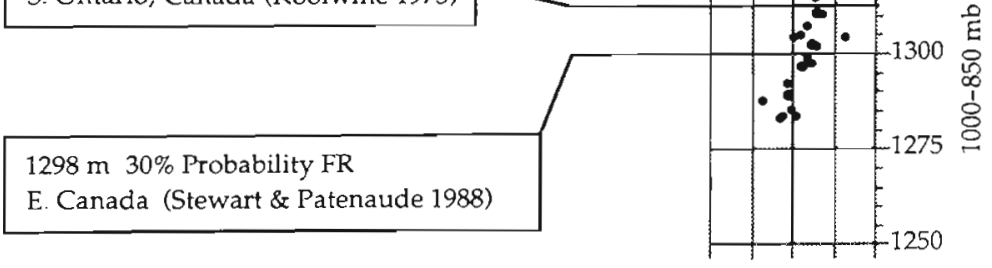

总 8 㝵 8 员 8

1000-500 mb Thickness
- SE Station Thickness

\section{Trends in FR/Sl occurrence}

Each station's time series was investigated to determine if any trends were present in either the event number or reported hours of FR or Sl. The data were

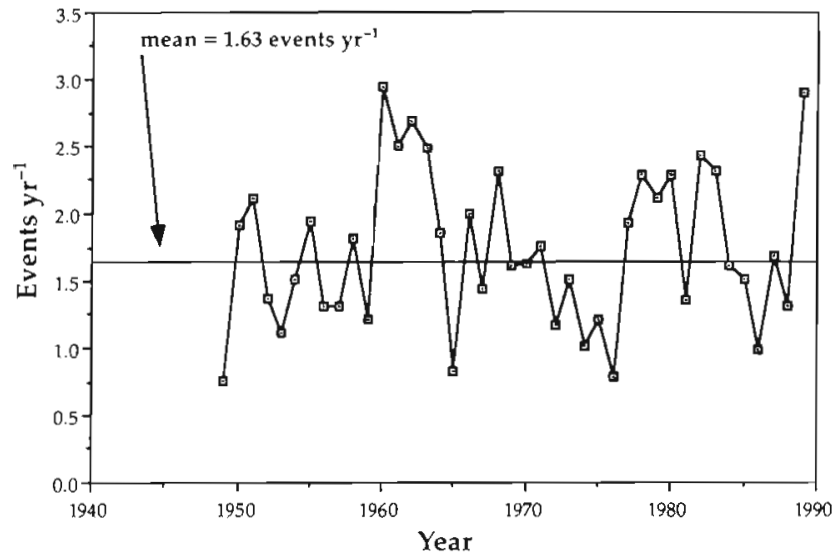

Fig. 14. Time series of the average annual number of FR/Sl events for the entire southeastern U.S analyzed using a simple least-square, linear regression with year as the independent variable. Only a few event number trends are significant $(\alpha=0.05)$ over the 40 yr period: Centerville, AL, Apalachicola, FL, Waycross, GA, New River, NC, and Lynchburg, VA. The 3 southern stations have positive trends, but Apalachicola and Waycross are based on only 3 events each, while Centerville has only operated since 1970. New River does show a modest increase in the number of events, while Lynchburg has the only significant decreasing trend $\left(-0.07\right.$ events $\left.\mathrm{yr}^{-1}\right)$. Stations with significant event number trends are generally the same ones with significant trends in either FR and/or Sl reported hours (Centerville, AL, New River, NC, Lynchburg, VA, Apalachicola, FL, Waycross, GA). Again, the slopes are generally positive, except in Lynchburg for both FR $\left(-0.46 \mathrm{~h} \mathrm{yr}^{-1}\right)$ and Sl $(-0.13 \mathrm{~h}$ $\left.\mathrm{yr}^{-1}\right)$. Notable significant increases are found in

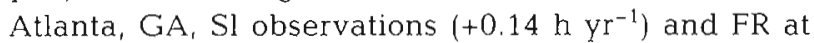
Huntsville, AL $\left(+0.35 \mathrm{~h} \mathrm{yr}^{-1}\right)$.

The average annual event frequency time series for the Southeast is shown in Fig. 14. High variability 
about the regional mean of 1.63 events $\mathrm{yr}^{-1}$ occurs throughout the record. High frequency years include the early 1960 s and 1988. Lower frequency years occur in the mid-1970s and in 1964. Over all years, there is no significant trend.

\section{Summary and conclusions}

On average, the Southeast has $1.6 \pm 1.7 \mathrm{FR} / \mathrm{Sl}$ events $\mathrm{yr}^{-1}$, ranging from zero events at 3 Florida stations (Tampa Bay, Key West, and Palm Beach) to 5.6 events $\mathrm{yr}^{-1}$ at Roanoke, VA. Most events occur in January, and December and February have slightly lower frequencies. Event duration is longest in December with $9.0 \pm 7.1 \mathrm{~h} \mathrm{event}^{-1}$, followed closely by January and February $\left(8.7 \pm 5.4\right.$ and $8.6 \pm 5.8$ h event $\left.^{-1}\right)$.

Based on 40 yr of climatological data, event distributions in the Southeast U.S. show 2 general features. A large $\mathrm{V}$-shaped wedge of high event frequency is observed over inland/mountain Virginia and North Carolina. The highest average is over 5 events $\mathrm{yr}^{-1}$ at Roanoke and Lynchburg, VA, Greensboro, NC, and Washington, DC. These high event frequencies decrease in the northern coastal regions (except in Washington, DC) and in the southern piedmont and lowlands. Two general decreasing gradients of FR and Sl events are observed: (1) north to south, and (2) mountain to coastal.

FR and $\mathrm{Sl}$ event duration is highest in the northern regions. Roanoke, VA, Greensboro, NC, and Washington, DC (Dulles) have the longest average durations, with the typical winter event lasting over $12 \mathrm{~h}$. Most of upland Virginia and North Carolina experience events of this length, and durations decline as one moves south.

The FR to Sl ratio is also divided into upland and coastal groups. Upland and piedmont stations have almost exclusively 2.0 or $2.5 \mathrm{FR}$ hours to $1.0 \mathrm{Sl}$ hour. However, the coasts are much different, where ratios vary widely. Washington, DC (National) is thought to be an example of warming from an urban heat island reducing the occurrence of $F R$.

Temperatures at the surface and at $850 \mathrm{mb}$ generally follow accepted theory. FR surface temperatures are just below freezing (from 271.0 to $272.5 \mathrm{~K}$ ). At $850 \mathrm{mb}$, FR temperatures are mostly above $273.0 \mathrm{~K}$ and warmer than those of $\mathrm{Sl}$, although some stations (particularly in Georgia) have the opposite tendency. Sl temperatures vary much more than FR temperatures at both the surface and the $850 \mathrm{mb}$ level, and are both higher and lower than FR temperatures.

Layer thicknesses, related directly to layer temperatures, are highly variable over the Southeast. The 1000 to $500 \mathrm{mb}$ thicknesses vary by more than $60 \mathrm{~m}$ over the interior Southeast, and southern stations have larger thicknesses. Thickness changes quite rapidly at the piedmont-lowland boundary. Thickness differences between $\mathrm{Sl}$ and FR are greater in the 850 to $700 \mathrm{mb}$ layer than in the 1000 to $850 \mathrm{mb}$ layer, supporting the theory that the hydrometeor state at the warm/cold boundary is important in determining surface precipitation type. Most Southeast stations have a thicker (warmer) 850 to $700 \mathrm{mb}$ layer for FR than for Sl. In Georgia, however, this is generally reversed the 850 to $700 \mathrm{mb}$ layer is cooler for FR).

Only a few stations had statistically significant trends ( $\alpha=0.05$ ) over the past $40 \mathrm{yr}$. Increasing numbers of events have occurred at Centerville, $\mathrm{AL}$, Waycross, GA, Apalachicola, FL, and New River, NC. Lynchburg, VA, was the only location with significantly decreasing numbers of events and reported SI and FR hours. Other notable increases were found in Atlanta, GA, Sl observations $\left(+0.14 \mathrm{~h} \mathrm{yr}^{-1}\right)$ and Huntsville, AL, FR observations $\left(+0.35 \mathrm{~h} \mathrm{yr}^{-1}\right)$.

Frozen precipitation has great economic influence and extensive study of it is required. This research is only the beginning of such an effort. For future work, we suggest the following topics: (1) a climatological study of this type for the entire United States, describing events, event durations and upper air conditions, (2) a synoptic-scale and meso-scale climatology of FR and $\mathrm{Sl}$ events to more precisely define conditions leading to these events and to aid in their forecasting, (3) studies that concentrate on specific parameters that are summarized here, such as height of the freezing level under varying conditions, evolution of precipitation type during events, or variation of surface pressure and winds during events.

Acknowledgments. This work was supported through a grant provided by the Southeast Regional Climate Center (NOAA \#NA26CP0329-02). A full report including specific station values is available by request (Research Paper \#052593) from the SERCC at this address: Southeast Regional Climate Center South Carolina Water Resources Commission, 1201 Main Street, Suite 1100, Columbia, SC 29201, USA, tel. (804) 737 0800. We thank Scott Webber (University of Delaware) for providing the NOAA Upper Air dataset, Chip Knappenburger (Office of the Virginia State Climatologist) for his analysis and quality assurance help, and both Tanya Larson and Beth Pierce for their organizational and graphics work.

\section{LITERATURE CITED}

Ackerman, B. (1985). Temporal march of the Chicago heat island. Bull. Am. met. Soc. 24: 547-554

Ackely, S. F., Itagaki, K. (1970). Distribution of icing in the Northeast's ice storm of 26-27 December 1969. Weatherwise 23: 274-279

Bennett, I. (1959). Glaze: its meteorology and climatology, geographical distribution, and economic effects. Technical Report EP-105, U.S. Army Quartermaster Research and 
Engineering Command, Environmental Protection Research Division, Natick, MA

Brooks, C. F. (1914). The ice storms of New England. Harvard University Press, Cambridge

Brooks, C. F. (1920). The nature of sleet and how it is formed. Mon. Weather Rev. 48: 69-72

Bryson, R. A., Hare, F. K. (1974). World survey of climatology, Vol. II, Climates of North America. Elsevier Scientific Publishing Co., Amsterdam

Davis, R. E., Gay, D. A. (1993). Freezing rain and sleet climatology of the southeastern U.S.A. (Research Paper \#052593) Southeast Regional Climate Center, Columbia, $\mathrm{SC}$

Donaldson, N. R., Stewart, R. E. (1989). On the precipitation regions within two storms affecting Atlantic Canada. Atmos.-Ocean 27: 108-129

Downs, A. A. (1938). Glaze damage in the birch-beechmaple-hemlock type of Pennsylvania and New York. J. For, 36: $63-70$

Eagleman, J. R. (1983). Severe and unusual weather. Van Nostrand Reinhold Co., Inc., New York

Heppner, P. O. G. (1992). Snow versus rain: looking beyond the 'magic' numbers. Weather Forecast. 7: 683-691

Huschke, R. E. (ed.) (1959). Glossary of meteorology. American Meteorology Society, Boston

Karl, T. R., Diaz, H. F, Kukla, G. (1988). Urbanization: its detection and effect in the United States climate record. J. Climate 1: 1099-1123

Koolwine, T. (1975). Freezing rain. M.Sc, thesis, University of Toronto

Lamb, H. H. (1955). Two-way relationship between the snow and ice limit and $1000-500 \mathrm{mb}$ thicknesses in the overlaying atmosphere. Quart. J. R. meteorol. Soc. 19: 354-355

Matsuo, T., Sasyo, Y., Sato, Y (1981). Relationship between types of precipitation on the ground and surface meteorological elements. J. meteorol. Soc. Japan 59: 462-475

Martner, B. E., Snider, J. B., Zamora, R. J., Byrd, G. P., Niziol, T. A., Joe, P. I. (1993). A remote-sensing view of a freezing-rain storm. Mon. Weather Rev. 121: 2562-2577

McNayr, J. S. (1944). Unusual ice storm in Louisiana, January 13-14, 1944. Bull. Am. met. Soc. 25: 196

McQueen, H. R., Keith, H. C. (1956). The ice storm of January $7-10,1956$ over the northeastern United States. Mon. Weather Rev. 84: 35-45
Murray, R. (1952). Rain and snow in relation to the 1000-700 $\mathrm{mb}$. and $1000-500 \mathrm{mb}$. thicknesses and the freezing level. Meteorol. Mag. 81: 5-8

National Climatic Data Center (NCDC) (1991). Surface airways hourly TD-3280 and airways solar radiation TD3281. U.S. Department of Commerce, National Oceanic and Atmospheric Administration (NOAA), Federal Building, Asheville, NC

National Climatic Data Center (NCDC) (1992). Monthly station normals of temperature, pressure, and heating and cooling degree days ${ }_{i}$ 1961-1990, Virginia. U.S. Department of Commerce, National Oceanic and Atmospheric Administration (NOAA), Federal Building, Asheville, NC

National Center for Atmospheric Research (NCAR) (1975). Northern hemisphere octagonal grid data. U.S. Department of Commerce, National Oceanic and Atmospheric Administration (NOAA), Boulder, CO

Okada, T. (1914). Notes on the formation of glaze. Mon Weather Rev. 42: 284-286

Spiegler, D. B., Fisher, G. E. (1971). A snowfall prediction method for the Atlantic seaboard. Mon. Weather Rev. 99 $311-325$

Stewart, R. E. (1985). Precipitation types in winter storms Pure appl. Geophys. 123: 597-609

Stewart, R. E. (1991). On the temperatures near and the motions of low-pressure centres in winter storms. Atmos. Res. 26: 33-54

Stewart, R. E. (1992). Precipitation types in the transition region of winter storms. Bull. Am. met. Soc. 73: 287-296

Stewart, R. E., King, P. (1987). Freezing precipitation in winter storms. Mon. Weather Rev. 115: 1270-1279

Stewart, R. E., Patenaude, L. M. (1988). Rain-snow boundaries and freezing precipitation in Canadian east coast winter storms. Atmos.-Ocean 26: 377-398

Stewart, R. E., Yiu, D. T. (1993). Distributions of precipitation and associated parameters across precipitation type transitions over southern Ontario. Atmos. Res. 29: 153-178

Tannehill, I. R. (1929). Wet and dry northers. Mon. Weather Rev. 57: $136-142$

Wallace, J. M., Hobbs, P. V. (1977). Atmospheric sciences: an introductory survey. Academic Press, Inc., New York

Young, W. R. (1978). Freezing precipitation in the southeastern United States. M.Sc thesis, Colorado State University, Fort Collins

Manuscript first received: June 30,1993

Revised version accepted: October 19, 1993 